\title{
Investor Sentiment and Size Effect
}

\section{Ge Li}

School of Business, Nanjing Normal University, Nanjing, China

Email: 15905161221@163.com

How to cite this paper: Li, G. (2020). Investor Sentiment and Size Effect. Open Journal of Social Sciences, 8, 252-266. https://doi.org/10.4236/jss.2020.87021

Received: June 22, 2020

Accepted: July 21, 2020

Published: July 24, 2020

Copyright $\odot 2020$ by author(s) and Scientific Research Publishing Inc. This work is licensed under the Creative Commons Attribution International License (CC BY 4.0).

http://creativecommons.org/licenses/by/4.0/

\begin{abstract}
This paper uses the two-stage least square method and uses the monthly data of investor sentiment and size effect from 2003 to 2019. Different from the linear model used in previous studies, this paper, based on the nonlinear model, explores the relationship between investor sentiment and size effect. The study finds that investor sentiment has explanatory power to size effect and they take on an inverted U-shaped relationship. Compared with the rising period of investor sentiment, the falling period of investor sentiment is more sensitive to size effect. In addition, this paper uses an alternative variable ISI of investor sentiment, and its empirical results are still robust.
\end{abstract}

\section{Keywords}

Investor Sentiment, Size Effect, Small Stocks, Size Premium, Size Factor, Risk Compensation

\section{Introduction}

A common theme in behavioral finance is that bounded rational investment can affect asset prices, a strong evidence is that arbitrage criticism (Shleifer, 2000; Gromb \& Vayanos, 2010) points out that arbitrageurs cannot eliminate mispricing due to the existence of fundamental risks, noise trader risks, synchronization risks, and other types of transaction costs, so excess returns exist in the market.

Size effect refers to the specific relationship between the size of a company and stock returns. The size effect anomaly was firstly proposed by Banz (1981), whose research finds that the returns and risk-adjusted returns of small stocks outperform those of large stocks. James \& Edmister (1983) demonstrate significant size effect under the condition of controlling trading volume, and the more active the stock trades, the higher the abnormal returns. Brown, Kleidon, \& Marsh (1983) analyze the size effect phenomenon on the basis of annual returns, and they be- 
lieve that size effect varies with years. Keim (1983) documents that the size effect is still seasonal, and about half of it comes from January effect every year.

The unusually significant size factor in China's A-share market also proves the existence of excess returns. Song \& Jin (1995) firstly propose that there is size effect in China's stock market. Chen et al. (2001) find that there is a significant negative correlation between the stock returns of Shanghai stock market and the size of the company. Zhang et al. (2004) verify the existence of size effect and further examine the explanatory power of size to stock return, and find that size effect is robust. Chen \& Liu (2010) conduct an empirical study on the basis of the company data from January 2007 to June 2009, which also reached the conclusion that there is size effect in Shanghai stock market. Wei (2014) selects the data of China's A-share market from 1996 to 2009 and also finds that the A-share market has size effect, but in some months, it has reversed size effect. Liu, Stambaugh, \& Yuan (2019), after considering the status quo of backdoor listing in China's A-share market, rank the market capitalization and eliminate $30 \%$ of the low-market capitalization, and find that size effect is still robust.

The explanations of size effect anomalies in previous literature mainly focus on systematic risk, default risk, idiosyncratic risk, bankruptcy risk, transaction cost and information asymmetry. In addition, investor sentiment can also be used as an influential factor. Swaminathan (1996) reports that investor sentiment's explanatory power in small stocks is better than that of large stocks. Lee et al. (1991), Neal \& Wheatley (1998) believe that the sentiment of individual investors is positively related to the changes in return of low-institution holding stocks and small cap stocks. Baker \& Wurgler (2006) indicates stocks that are highly subjective and difficult to arbitrage are more susceptible to investor sentiment, such as small stocks. Barberis (2018) roughly divides the theoretical framework of behavioral finance into three frameworks: beliefs, preferences, and cognitive constraints, among of them, belief framework believes that investors will distort their beliefs due to changes in their emotions, making further difference to size effect.

The contributions of this paper are as follows. Firstly, there is relatively little research on investor sentiment and size premium, thus this paper, to some extent, makes contributions to this field. Secondly, for those relevant documents, most of them study their relationship from the perspective of risk taking, but this paper finds that only risk taking cannot explain the relationship between the two; Thirdly, the previous documents mainly use linear equation model to analyze the relationship between investor sentiment and size effect. However, this paper shows evidence that investor sentiment and size effect are not simple linear relationships, but inverted $\mathrm{U}$-shaped relationship.

The remainder of this study proceeds as follows. Section 2 is the theoretical background. Section 3 is literature review. Section 4 is empirical analysis and the Section 5 is conclusion. 


\section{Literature Review}

\subsection{Investor Sentiment and Size Effect}

There are two main types of definitions of investor sentiment in academic research: 1) the degree to which noise traders deviate from rational arbitrageurs' beliefs about future stock price expectations (De Long et al., 1990). 2) a belief formed by investors based on their expectation of future cash flow and investment risks of assets (Baker \& Wurgler, 2006).

Johnson \& Tversky (1983) put forward the affective generalization hypothesis, which holds that the emotional state of decision makers will be generalized to the later decision-making judgment, and Isen \& Patrik (1983) put forward the mood maintenance hypothesis, which holds that decision makers will avoid making decision-making behaviors that can bring the opposite experience in order to maintain their emotional state to the greatest extent. Therefore, investor sentiment will have an impact on investor decisions. Stein \& Jeremy (1996) believe that investor sentiment causes stocks prices to deviate from their fundamental values.

Brown \& Cliff $(2004,2005)$ use closed-end fund discount as a proxy of investor sentiment. Through the regression between investor sentiment and stock returns which is divided into small cap stocks and large cap stocks, they do not find the predictive power of investor sentiment. While Baker \& Wurgler (2006) document that with the increase of investor sentiment, the returns of small stocks and growth stocks will decline. When investor sentiment is low, size effect is more significant small stocks, but when sentiment is high, the relationship is weakened.

\subsection{Theoretical Analysis}

The existing researches on the relationship between investor sentiment and size premium are mainly analyzed from the perspectives of risk taking, short selling restriction and sentiment transfer hypothesis.

From the perspective of risk taking, Banz (1981) is the first to study the phenomenon of size premium. He finds that the returns of small cap stocks on the New York Stock Exchange from 1926 to 1975 are significantly higher than those of large cap stocks. He points out that the lack of information on small cap stocks makes investors face greater risks, so investors demand high returns. Barry \& Brown (1984) point out that large stocks often have less information asymmetry than small stocks due to more information disclosure and analyst reports. Schwarz \& Clore (1983) put forward the hypothesis of emotional information transmission, people always tend to make decisions consistent with the current mood. In other words, in an optimistic mood, investors will be willing to relax restrictions and dilute their aversion to risks, thus showing a substantial increase in trading volume in stock transactions. Bassi et al. (2013) further reveal that investors are more willing to take greater risks and make more radical decision-making behavior under optimistic mood. Baker \& Wurgler (2006) document that highly sub- 
jective and difficult to arbitrage value stocks are more sensitive to investor sentiment when studying the relationship between investor sentiment and crosssectional stock returns. When investor sentiment is low, the follow-up returns of small stocks, high volatility stocks, unprofitable stocks, non-dividend paying stocks, extreme growth stocks and non-performing stocks are relatively high, which is consistent with the initial low pricing of these stocks. She \& Chen (2005) explain the "small cap effect" from the perspective of return volatility, that is, if small cap stocks have high volatility, investors will think that they are at greater risk and will require higher risk compensation, thus leading to the "small cap effect". Qadan \& Aharon (2019) believe that market participants tend to overestimate small stocks relative to large ones during the risk appetite period. The study on the relationship between investor sentiment and size premium using data of day, week and month shows that investor sentiment can not only explain size premium, but also predict size premium.

From the perspective of short selling restrictions, Zuo \& Liu (2011) believe that under the combined effect of short selling restrictions and investors' heterogeneous beliefs, overvalued asset prices lead to a decrease in future returns. Gu et al. (2018) find that the particularity of the trading system in China's stock market makes the short selling restrictions faced by investors significantly higher than those in mature stock markets in Europe and the United States. The short selling restrictions restrict the arbitrage behavior of rational investors, making incorrectly priced stocks continuously overvalued or undervalued in a longer period of time, thus strengthening the market anomaly. After the introduction of margin trading and short selling system, the trend of small cap stocks and large cap stocks has obviously diverged.

Zhang et al. (2005) compare the similarities and differences of the size effect of Chinese and American stock markets, pointing out that market manipulation and the prevalence of speculation are the reasons for the anomalies of small companies in Chinese stock markets. Zhang et al. (2007) confirm that excessive speculation is the cause of the size effect by comparing the change of turnover rate of different size stock portfolios before and after the size effect disappears, while the excess return of small market capitalization stock is the compensation for the noise trading risk caused by excessive investment.

Based on these opinions, this paper regards investor sentiment as an influential factor of size effect. The theoretical analysis shows that the relationship is mainly analyzed from the perspective of risk taking, short selling restriction and sentiment transfer hypothesis, among of these, the existing literature take the risk taking as a source of the relationship between investor sentiment and size effect. Hence, this paper considers risk taking as the result of the relationship between two, thinking that investor sentiment impacts investor's attitude of risk taking, and makes a further impact on decision making of investor's buying and selling stocks, bringing about the size effect.

This paper aims to examine the relationship between investor sentiment and 
size effect by two-stage least square method. Given that previous documents mainly take linear model to test their relationship, so this paper firstly takes linear model to examine, finding that investor sentiment has no correlation with size effect as a result of incorrect model setting. Linear model doesn't pass link test; therefore, this paper adopts non-linear model and take an alternative variables of investor sentiment to test its robustness.

\section{Data Source and Variable Measurement}

\subsection{Investor Sentiment Measures}

Investor sentiment measurement can be divided into single index and compound index. Single indicators include closed-end fund discount, liquidity indicator, half-year momentum, Twitter social platform published content, variance of analyst earnings forecast, Maneuverability accrual, Internet search volume. Composite indicators mainly use principal component analysis, including Baker \& Wurgler's (2006) principal component analysis of closed-end fund discount rate, turnover, IPO first-day return rate, market transaction volume and dividend premium, and Yi \& Mao's (2009) principal component analysis of closedend fund discount, market transaction volume, IPO number and first-day earnings, consumer confidence index and new investors' account opening number. According to Hua et al. (2016), Tobin Q, momentum, market-to-book ratio, turnover rate, price-earnings ratio and principal component analysis of fundamental factors of the company. Other methods, such as Chi et al. (2012), based on extended Kalman filter (KEF) method, construct investor sentiment index to filter market noise; Liu \& Wang (2016) used ETF market trading volume as one of the proxy variables, and used partial least squares (PLS) to construct investor sentiment.

In this paper, Investor sentiment adopts CICSI index constructed by Yi \& Mao (2010), which is based on BW index (Baker \& Wurgler, 2006), the result is this index can reflect the change of Chinese investors sentiment and its data are available. Specifically, principal component variables include closed-end fund discount, trading volume, the number of IPOs, IPO average first-day return, number of new investor accounts opened, consumer confidence index and other variables, and the influence of macroeconomic factors is eliminated, which can better measure investor sentiment in Chinese stock market. Based on the availability of data, sample period is from 2003.03 to 2019.12 , and the sample is selected from Chinese A-share Market. CICSI data are sourced from CSMAR database and are processed by logarithm.

\subsection{Size Effect Measures}

Yang \& Xing (1998) use the stock equity as a measure of the size. The average value of the stock equity at the end of the stock period and the beginning of the stock period is taken and analyzed by the logarithm of the stock equity. $\mathrm{He}$ (2000) divides the size by market capitalization and total stock equity. Chen et al. 
(2001) measure the size by market capitalization. Zhou (2002) takes the total market capitalization, circulation market capitalization, total assets and main business income as the measurement indicators of size. We can see that many documents rank size of company according to circulating market captalization such as Liu \& Wang (2016) and Meng \& Chang (2019).

Given that in recent years, circulation market capitalization has used more frequently compared to total market capitalization in relevant literature, SMB is the difference between large stocks return and small stocks return weighted by circulation market capitalization. Based on the availability of data, sample period is from 2003.03 to 2019.12, and the sample is selected from Chinese A-share Market, SMB data come from Fama-French three factor model index in CSMAR database.

\subsection{Control Variables Measures}

Control variables include value factor, market risk factor and macroeconomic variables. The value factor (HML) is the difference between the monthly returns of the combination with high book-to-market value ratio and the combination with low book-to-market value ratio weighted by the circulation market capitalization, while the market risk factor (MRP) is the difference between the monthly market return weighted by the circulation market capitalization and the monthly risk-free interest rate. Macroeconomic variables include Consumer Price Index (CPI), Industrial Producer Price Index (IPPI), Industrial Value Added (IAV) and Macroeconomic Prosperity Index (MEBI). The reason for adopting these macroeconomic variables is that they are proxy variables of economic fundamentals and are widely used in the study of investor sentiment and size effect (Yi \& Mao, 2010; Meng \& Chang, 2019). Based on the availability of data, sample period is from 2003.03 to 2019.12 , and the sample is selected from Chinese Ashare Market. The data of HML, MRP come from Fama-French three factor model index in CSMAR database, and CPI, IPPI, IAV and MEBI also come from CSMAR database and all are processed by logarithm.

\section{Empirical analysis}

\subsection{Descriptive Statistics}

Table 1 reports the descriptive statistics of variables. As can be seen from Table 1 , there are total 203 observation items, and the minimum value of size factor ( $\mathrm{SMB}$ ) is -0.2250 , the maximum value is 0.2138 . The range of investor sentiment (CICSI) is from 3.0397 to 3.9497 , its mean is 3.5560 . The value of market risk factor (MRP) is from -0.2624 to 0.2244 . Value factor (HML) ranges from -0.1551 to 0.1638 . Except consumer price index (CPI), the range and value of remaining variables is close, whose districts are between 4.50 and 4.71. After these variables are processed by logarithm, the standard deviation and the standard deviation of size effect are relatively small and the data are relatively stable. 


\subsection{Correlation Analysis}

Table 2 reports the correlation between variables, it shows that SMB is significantly correlated with MRP, HML, IPPI and MEBI at 5\%, 1\%, 5\% and 5\% levels respectively. CICSI is not related to other variables. MRP has strong correlation with CPI and IPPI at $1 \%$ levels respectively. CPI is also significantly related to IAV, IPPI and MEBI at $1 \%$ levels respectively. Meanwhile, IPPI has a obvious relation with MEBI.

\subsection{Model Construction and Empirical Test}

\subsubsection{The Establishment of Model}

Qadan \& Aharon (2019), Baker \& Wurgler (2006), Zhou (2002) and others have mostly adopted linear models when studying the relationship between investor sentiment and size effect. Therefore, this paper firstly builds a linear model equation between investor sentiment and size premium on the basis of previous research model construction methods. Given this paper finds that investor sentiment (CICSI) is a random walk model with drift term through regression, so I

Table 1. Descriptive statistics of variables.

\begin{tabular}{cccccc}
\hline Variable & Obs & Mean & Std. Dev. & Min & Max \\
\hline SMB & 203 & 0.0056 & 0.0543 & -0.2250 & 0.2138 \\
CICSI & 203 & 3.5560 & 0.2304 & 3.0397 & 3.9497 \\
MRP & 203 & 0.0074 & 0.0794 & -0.2624 & 0.2244 \\
HML & 203 & 0.0015 & 0.0337 & -0.1551 & 0.1638 \\
CPI & 203 & 4.6309 & 0.0183 & 4.5870 & 4.6886 \\
IAV & 203 & 2.4400 & 0.4020 & 0.7419 & 3.1442 \\
IPPI & 203 & 4.6218 & 0.0426 & 4.5196 & 4.7014 \\
MEBI & 203 & 4.6000 & 0.0320 & 4.5249 & 4.6444 \\
\hline
\end{tabular}

Table 2. Correlation.

\begin{tabular}{ccccccccc}
\hline Variable & SMB & CICSI & MRP & HML & CPI & IAV & IPPI & MEBI \\
\hline SMB & 1.000 & & & & & & & \\
CICSI & 0.048 & 1.000 & & & & & & \\
MRP & $0.126^{*}$ & 0.013 & 1.000 & & & & & \\
HML & $-0.55^{* * *}$ & -0.082 & -0.095 & 1.000 & & & & \\
CPI & -0.039 & 0.046 & $-0.22^{* * *}$ & 0.033 & 1.000 & & \\
IAV & 0.094 & -0.062 & -0.031 & -0.042 & $0.208^{* * *}$ & 1.000 & & \\
IPPI & $-0.159^{* *}$ & -0.074 & $-0.21^{* * *}$ & $0.141^{* *}$ & $0.557^{* * *}$ & -0.045 & 1.000 & \\
MEBI & $-0.155^{* *}$ & -0.054 & -0.088 & $0.147^{* *}$ & $0.450^{* * *}$ & 0.002 & $0.867^{* * *}$ & 1.000 \\
\hline
\end{tabular}

Note: ${ }^{*}{ }^{* *}$ and ${ }^{* * *}$ are significant at $10 \%, 5 \%$ and $1 \%$ levels respectively. 
take a two-stage least squares regression model. Although some studies have added variables such as $\mathrm{SMB}_{\mathrm{t}-1}$ and January effect to the equation, after empirical research, $\mathrm{SMB}_{\mathrm{t}}$ and $\mathrm{SMB}_{\mathrm{t}-1}$ and January effect are not significant, and the empirical process is not listed in the article, so the model does not consider these two explanatory variables. In addition, through correlation analysis, $\mathrm{SMB}_{\mathrm{t}}$ has no significant correlation with $\mathrm{CPI}_{\mathrm{t}}$ and $\mathrm{IAV}_{\mathrm{t}}$, so the control variables only include $\mathrm{HML}_{\mathrm{t}}, \mathrm{MRP}_{\mathrm{t}}, \mathrm{IPPI}_{\mathrm{t}}$ and MEBI $\mathrm{I}_{\mathrm{t}}$, and Equation (1) is as follows:

$$
\begin{aligned}
& \operatorname{CICSI}_{\mathrm{t}}=\partial_{0}+\partial_{1} \mathrm{CICSI}_{\mathrm{t}-1} \\
& \operatorname{SMB}_{\mathrm{t}}=\beta_{0}+\beta_{1} \text { CICSI }_{\mathrm{t}-1}+\sum \beta_{\mathrm{i}} \text { Control }_{\mathrm{t}}
\end{aligned}
$$

where $\beta_{\mathrm{i}}$ refers to coefficient of different control variables, subscript $t$ refer to the year. CICSI $I_{t}$ and CICSI $_{t-1}$ show the investor sentiment in $t$ and $t-1$ time, $\mathrm{SMB}_{\mathrm{t}}$ represents size effect in $t$ time.

\subsubsection{Empirical Test}

The data on investor sentiment and size effect are from March 2003 to December 2019. According to the change trend of investor sentiment in Figure 1, I sort investor sentiment into an upward period and a downward period, and sample data are divided into four periods: 2003 to 2004, 2005-2007, 2008-2011, and 2012-2019. In addition to the changing trend of investor sentiment from Figure 1, Figure 2 shows the constant change of size effect in different time periods.

Table 3 shows the regression result of model. The empirical results show that both CICSI $_{t}$ and CICSI $_{t-1}$ have the positive direction in both total period and subperiods. The change directions of the two are consistent and statistically significant, passing the significance test of $1 \%$. It can also be seen from Table 3 that the empirical results of investor sentiment and size effect are not significant in

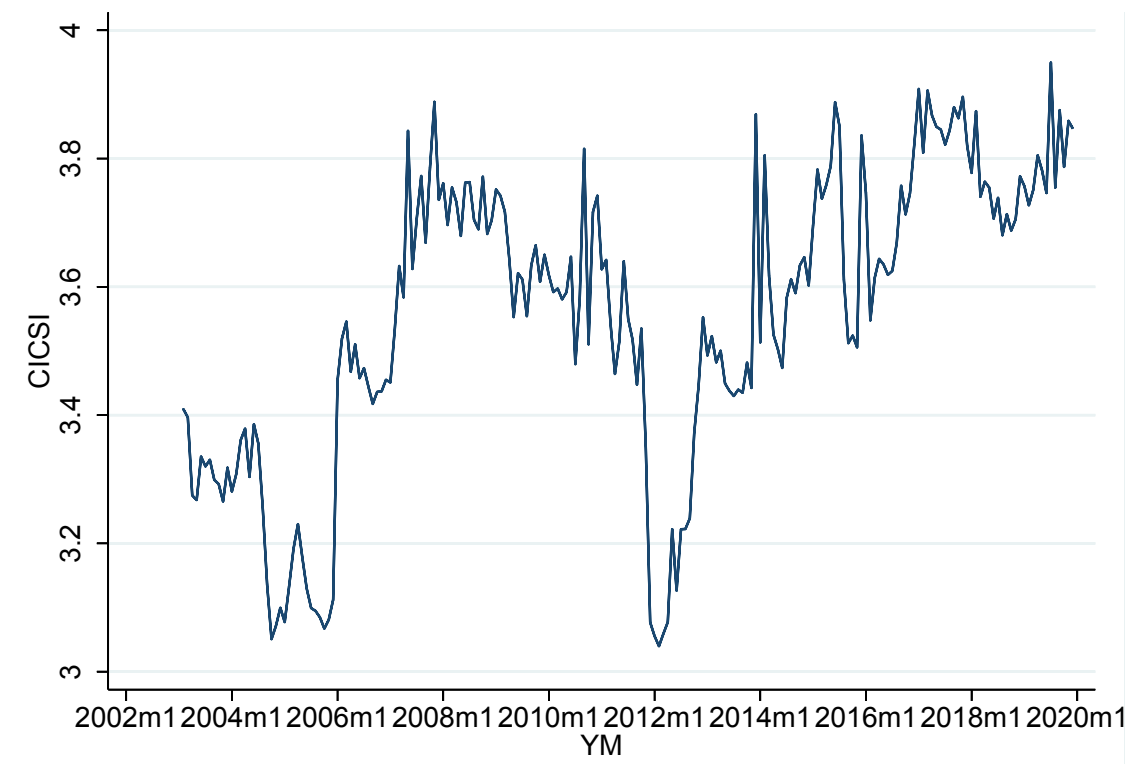

Figure 1. Investor sentiment. 


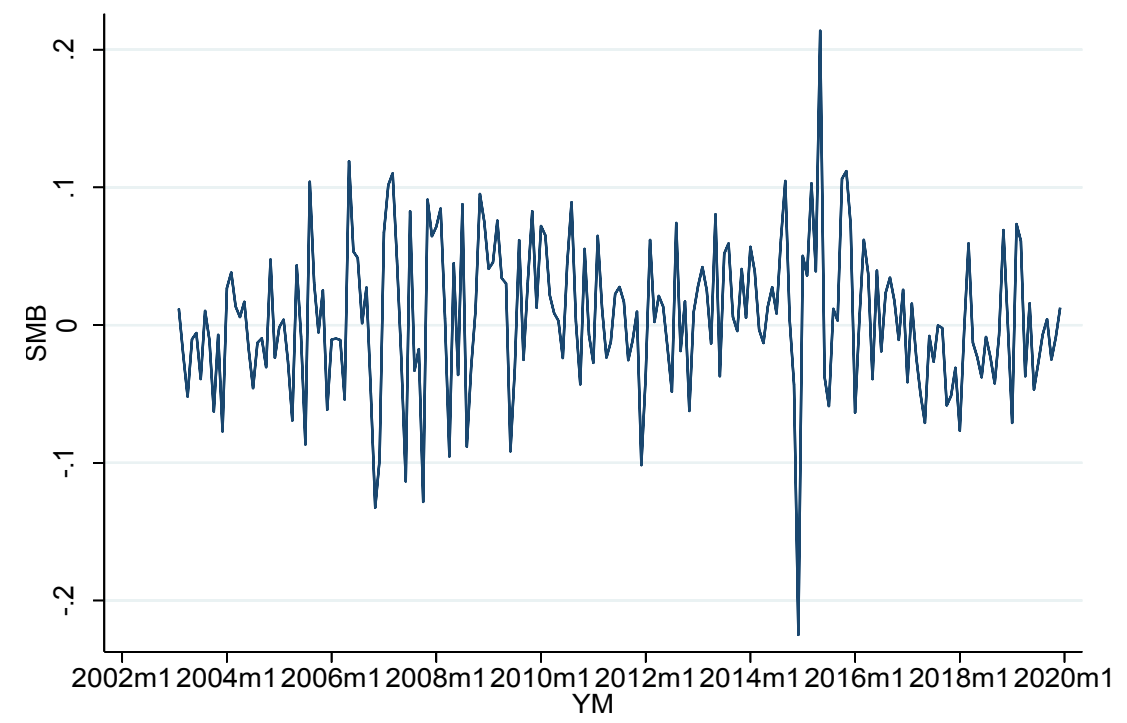

Figure 2. Size effect.

Table 3. Regression test without quadratic term.

\begin{tabular}{|c|c|c|c|c|c|c|}
\hline & 2003-2019 & & 2003-2004 & $2005-2007$ & $2008-2011$ & $2012-2019$ \\
\hline \multirow[t]{4}{*}{ CICSI } & LCICSI & $0.912^{* * *}$ & $0.859^{* * *}$ & $0.911^{\star * *}$ & $0.790^{* * *}$ & $0.8493^{* * *}$ \\
\hline & Constant & $0.315^{* * *}$ & 0.450 & 0.323 & 0.749 & $0.556^{* * *}$ \\
\hline & R-square & 0.827 & 0.673 & 0.841 & 0.386 & 0.775 \\
\hline & F-stat & 954.54 & 41.19 & 173.99 & 28.34 & 319.43 \\
\hline \multirow[t]{8}{*}{ SMB } & LCICSI & -0.002 & -0.063 & -0.067 & 0.108 & -0.012 \\
\hline & MRP & 0.044 & 0.003 & 0.082 & 0.018 & 0.047 \\
\hline & HML & $-0.852^{\star * *}$ & $-0.650^{* * *}$ & 0.296 & $-0.769^{* * *}$ & $-1.069^{\star * *}$ \\
\hline & IPPI & -0.047 & -0.364 & 1.229 & -0.039 & -0.344 \\
\hline & MEBI & -0.069 & 1.505 & 3.237 & 0.001 & 0.163 \\
\hline & Constant & 0.545 & -5.045 & -20.4299 & -0.202 & $0.886^{*}$ \\
\hline & R-square & 0.310 & 0.551 & 0.101 & 0.254 & 0.692 \\
\hline & F-stat & 17.57 & 3.92 & 0.65 & 2.79 & 40.03 \\
\hline
\end{tabular}

Note: ${ }^{* *}$ and ${ }^{* * *}$ are significant at $10 \%, 5 \%$ and $1 \%$ levels respectively.

each period, showing a weak correlation between investor sentiment and size effect. When investor sentiment is in the upward period (2005-2007, 2012-2019), the relationship between investor sentiment and size effect in the two periods is opposite, and their coefficients are -0.067 and -0.012 respectively less than zero, reflecting the reversal of size effect in the upward period. When the investor sentiment is in a downward period (2003-2004, 2008-2011), the relationship between investor sentiment and size effect shows discrepancy, it may be the reason 
that in the subperiod of 2003-2004, its data are not complete, and thus don't reflect its trend correctly. However, in the downward subperiod of 2008-2011, the coefficient between investor sentiment and size effect is 0.108 more than zero, showing the existence of size effect in the downward period. Thus it can be seen that compared with the rising stage of investor sentiment, investor sentiment is more sensitive to size effect when it is in the falling stage. This empirical result is partially the same as Baker \& Wurgler (2006) research, who found that size effect is not significant when investor sentiment rises, and size effect only occurs when investors sentiment is low. In each period, the size effect has a weak positive correlation with the market risk factor $\left(\mathrm{MRP}_{\mathrm{t}}\right)$, its coefficient is positive, indicating that when market risk rises $\left(\mathrm{MRP}_{\mathrm{t}}\right)$, size effect $\left(\mathrm{SMB}_{\mathrm{t}}\right)$ also rises. Except 2005-2007, the value factor and the size factor have significant negative correlation at $1 \%$ levels. While size effect $\left(\mathrm{SMB}_{\mathrm{t}}\right)$ has no significant correlation with Macroeconomic Prosperity Index (MEBI) and Industrial Producer Price Index (IPPI) in total period and subperiod period. Overall, the regression result is not significant.

After the model setting test, I find that linear model setting itself have problems. The connection test shows that linear model does not reflect the significant relationship between investor sentiment and size effect. By adding quadratic term, the model becomes more significant.

Table 4 shows the regression result with quadratic term, the empirical results indicate that both CICSI $_{t}$ and CICSI $_{t-1}$ have the positive relationship in both total

Table 4. Regression test with quadratic term.

\begin{tabular}{|c|c|c|c|c|c|c|}
\hline & 2003-2019 & & 2003-2004 & $2005-2007$ & 2008-2011 & $2012-2019$ \\
\hline \multirow[t]{4}{*}{ CICSI } & LCICSI & $0.912^{* * *}$ & $0.859^{* * *}$ & $0.911^{* * *}$ & $0.790^{* * *}$ & $0.849^{\star * *}$ \\
\hline & Constant & $0.315^{\star * *}$ & 0.450 & 0.323 & 0.749 & $0.556^{* * *}$ \\
\hline & R-square & 0.827 & 0.673 & 0.841 & 0.386 & 0.775 \\
\hline & F-stat & 954.54 & 41.19 & 173.99 & 28.34 & 319.43 \\
\hline \multirow[t]{9}{*}{ SMB } & LCICSI & $0.771^{* * *}$ & -4.502 & 2.429 & 3.709 & 0.991 \\
\hline & LCICSI2 & $-0.111^{\star * *}$ & 0.684 & -0.371 & -0.500 & -0.143 \\
\hline & MRP & 0.039 & 0.018 & 0.055 & 0.035 & 0.018 \\
\hline & HML & $-0.852^{\star * *}$ & $-0.645^{\star * *}$ & 0.187 & $-0.674^{* *}$ & -1.088 \\
\hline & IPPI & 0.017 & -0.576 & 2.136 & 0.049 & -0.232 \\
\hline & MEBI & -0.132 & $1.729^{\star * *}$ & $5.142^{*}$ & -0.138 & -1.088 \\
\hline & Con & -0.802 & 2.104 & $-37.613^{\star *}$ & -6.442 & -1.259 \\
\hline & R-square & 0.322 & 0.586 & 0.158 & 0.265 & 0.7110 \\
\hline & F-stat & 15.42 & 3.53 & 0.87 & 2.40 & 36.09 \\
\hline
\end{tabular}

Note: ${ }^{\star},{ }^{*}$ and ${ }^{* *}$ are significant at $10 \%, 5 \%$ and $1 \%$ levels respectively. 
periods and subperiods, and its relationship is consistent and statistically significant, passing the significance test of $1 \%$. In the total period (2013-2019), there is a positive correlation between $\mathrm{SMB}_{\mathrm{t}}$ and $\mathrm{CICSI}_{\mathrm{t}-1}$ primary term, while there is a negative correlation between $\mathrm{SMB}_{\mathrm{t}}$ and $\mathrm{CICSI}_{\mathrm{t}-1}$ quadratic term, showing that investor sentiment and size effect are inverted U-shaped. Compared with the investor sentiment in the rising stage (2005-2007, 2012-2019), the absolute value of $\mathrm{CICSI}_{\mathrm{t}-1}$ quadratic term's coefficient 0.500 and $\mathrm{CICSI}_{\mathrm{t}-1}$ primary term of coefficient 3.709 are larger than 0.371 or 0.143 in the falling stage (2008-2011), indicating that the investor sentiment in the falling stage is more sensitive to size effect. Market risk factor (MRP) has weak positive correlation with size factor (SMB) in each period, while value factor (HML) has significant negative correlation with size effects except 2004-2005. Industrial Producer Price Index (IPPI) has no significant relationship with size effect, while Macroeconomic Prosperity Index (MEBI) has significant relationship with size effect partly.

This paper takes risk compensation to explain size effect, but the inverted U-shaped shows the existence of size effect reversal which can not be explained by risk taking. Therefore risk taking is not enough to be the main cause of the relationship of investor investment and size effect.

\subsection{Robustness Test}

In order to investigate whether the relationship between investor sentiment and size effect is robust, this paper adopts ISI as investor sentiment's proxy. ISI (Wei, Xia, \& Sun, 2014) based on BW model to select 6 sentiment indicators such as market turnover rate, and uses principal component analysis to construct. The differences between ISI variable and CICSI variable are as follows: 1) The time points of six emotional indexes selected by ISI are different from CICSI, six variables of ISI are $\mathrm{NA}_{\mathrm{t}}, \mathrm{TURN}_{\mathrm{t}-1}, \mathrm{CCI}_{\mathrm{t}-1}, \mathrm{DCEF}_{\mathrm{t}-1}, \mathrm{NIPO}_{\mathrm{t}}, \mathrm{RIPO}_{\mathrm{t}}$, while CICSI is $\mathrm{NLA}_{t-1}, \mathrm{TURN}_{\mathrm{t}-1}, \mathrm{CCI}_{\mathrm{t}}, \mathrm{DCEF}_{\mathrm{t}}, \mathrm{NIPO}_{\mathrm{t}}, \mathrm{RIPO}_{\mathrm{t}} ; 2$ ) ISI uses orthogonal regression to eliminate the impact of macro-economy on emotional indicators, while CICSI uses regression of 6 emotional variables and 4 macro-economic variables to eliminate the impact of macro-economy.

From Table 5, we can see that the total results of the robustness test in Table 5 are almost the same as those of the quadratic regression in Table 4 in total period (2003-2019), investor sentiment and size effect have an inverted U-shaped relationship. Investor sentiment has a greater impact on size effect in the downward period (2008-2011) than in the upward period (2005-2007, 2012-2019).

To sum up, there is a significant inverted $U$-shaped relationship between investor sentiment and size effect in total period, which is different from many previous studies and is not likely to be explained by risk compensation. Size effect rises first and then falls no matter what investor sentiment rises or falls. For the rising stage, an explanation is that as small stocks have higher risks, investors demand higher compensation, which leads to higher premium for small stocks (Qadan \& Aharon, 2019), but when investor sentiment overreacts, 
Table 5. Regression result of robustness test.

\begin{tabular}{ccccccc}
\hline & $2003-2019$ & & $2003-2004$ & $2005-2007$ & $2008-2011$ & $2012-2019$ \\
\hline ISI & LISI & $0.012^{* * *}$ & 0.020 & $0.011^{* * *}$ & $0.009^{* * *}$ & $0.012^{* * *}$ \\
& Con & $3.195^{* * *}$ & 2.730 & $3.119^{* * *}$ & $3.474^{* * *}$ & $3.263^{* * *}$ \\
& R-square & 0.661 & 0.300 & 0.737 & 0.232 & 0.600 \\
& F-stat & 389.13 & 8.56 & 92.46 & 13.61 & 139.43 \\
LMB & LISI & $0.001^{* *}$ & -0.096 & 0.001 & -0.006 & $-0.002^{* *}$ \\
& LISI2 & $-4.22 \mathrm{e}-06^{* *}$ & 0.002 & $-6.56 \mathrm{e}-06$ & 0.0001 & $0.00001^{* *}$ \\
& MRP & 0.046 & 0.035 & -0.050 & 0.0563 & 0.037 \\
& HML & $-0.861^{* * *}$ & $-0.672^{* * *}$ & 0.209 & $-0.782^{* * *}$ & $-1.069^{* * *}$ \\
& IPPI & -0.081 & -0.216 & 1.087 & 0.125 & -0.079 \\
& MEBI & 0.003 & $1.224^{*}$ & 4.639 & -0.226 & -0.057 \\
Con & 0.346 & -3.338 & -26.469 & 0.621 & 0.690 \\
R-square & 0.333 & 0.605 & 0.266 & 0.244 & 0.710 \\
F-stat & 16.19 & 3.82 & 1.69 & 2.15 & 35.84 \\
\hline
\end{tabular}

Note: ${ }^{*}{ }^{* *}$ and ${ }^{* * *}$ are significant at $10 \%, 5 \%$ and $1 \%$ levels respectively.

investors keep rising stock prices, and the high valuation of small stocks leads to lower returns, which is reflected in lower size effect (Baker \& Wurgler, 2006). Moreover, value factor in some periods has strong negative correlations with size effect, indicating value factor can also explain size factor to some extent. In addition, this empirical research shows the existence of size effect reversal.

\section{Conclusion}

This paper explores the relationship between investor sentiment and size effect through two-stage least square method, and uses investor sentiment ISI to replace variable CICSI to test the result's robustness. Through robustness test, it further confirms the inverse U-shaped relationship between investor sentiment and size effect. Although the linear model is more convenient to explain the relationship between investor sentiment and size effect by using the influence mechanism, however, the empirical results of the linear model show that there is no significant relationship between investor sentiment and size effect, and the model setting is biased. Therefore, this paper adopts the model with the quadratic term of investor sentiment lag period. The empirical results show that the modified model is more explanatory and significant. Compared with the rising period of investor sentiment, when investor sentiment falls, the size effect is more easily affected by investor sentiment, and there is a size effect reversal either in the rising period or in the falling period.

Though we can use risk premium and overreaction to explain the size effect 
reversal, the defect of this paper is that the inverted U-shaped relationship between investor sentiment and size effect cannot be explained clearly by theory. Whether considering time variables or not, when investor sentiment is in the rising or falling stage, the size effect shows a reverse trend of rising first and then falling, this is also one aspect different from other research results, which we need to solve in the future.

\section{Conflicts of Interest}

The author declares no conflicts of interest regarding the publication of this paper.

\section{References}

Baker, M., \& Wurgler, J. (2006). Investor Sentiment and the Cross-Section of Stock Returns. The Journal of Finance, 61, 1645-1680. https://doi.org/10.1111/j.1540-6261.2006.00885.x

Banz, R. W. (1981). The Relationship between Return and Market Value of Common Stocks. Journal of Financial Economics, 9, 3-18. https://doi.org/10.1016/0304-405X(81)90018-0

Barberis, N. (2018). Psychology-Based Models of Asset Prices and Trading Volume. In Handbook of Behavioral. Economics (Vol. 1, pp. 79-175). Amsterdam: Elsevier. https://doi.org/10.1016/bs.hesbe.2018.07.001

Barry, C. B., \& Brown, S. J. (1984). Differential Information and the Small Firm Effect. Journal of Financial Economics, 13, 283-294. https://doi.org/10.1016/0304-405X(84)90026-6

Bassi, A., Colacito, R., \& Fulghieri, P. (2013). An Experimental Analysis of Weather and Risk Attitudes in Financial Decisions. Review of Financial Studies, 26, 1824-1852. https://doi.org/10.1093/rfs/hht004

Brown, G. W., \& Cliff, M. T. (2004). Investor Sentiment and the Near-Term Stock Market. Journal of Empirical Finance, 11, 1-27. https://doi.org/10.1016/j.jempfin.2002.12.001

Brown, G. W., \& Cliff, M. T. (2005). Investor Sentiment and Asset Valuation. Journal of Business, 78, 405-440. https://doi.org/10.1086/427633

Brown, P., Kleidon, A. W., \& Marsh, T. A. (1983). New Evidence on the Nature of SizeRelated Anomalies in Stock Prices. Journal of Financial Economics, 12, 33-56. https://doi.org/10.1016/0304-405X(83)90026-0

Chen, W. J., \& Liu, X. Y. (2010). An Empirical Study on the Size Effect of Shanghai Stock Market. Accounting and Finance, No. 2, 7-11.

Chen, X. Y., Zhang, T. Y., \& Chen, D. H. (2001). Cross-Sectional Multivariate Analysis of Expected Stock Returns: Empirical Evidence from China's Securities Market. Financial Research, No. 6, 22-35.

Chi, L. X., Zhang, G. S., Zhuang, X. T., \& Song, D. L. (2012). Investor Sentiment Index and Stock Market-Research Based on Extended Kalman Filter. Journal of Industrial Engineering and Engineering Management, 26, 122-128 + 165.

De Long, J. B., Shleifer, A., Summers, L. H., \& Waldmann, R. J. (1990). Noise Trader Risk in Financial Markets. Journal of Political Economy, 98, 703-738. https://doi.org/10.1086/261703

Gromb, D., \& Vayanos, D. (2010). Limits to Arbitrage. Annual Review of Financial Eco- 
nomics, 2, 251-275. https://doi.org/10.1146/annurev-financial-073009-104107

Gu, M., Kang, W., \& Xu, B. (2018). Limits of Arbitrage and Idiosyncratic Volatility: Evidence from China Stock Market. Journal of Banking and Finance, 86, 240-258. https://doi.org/10.1016/j.jbankfin.2015.08.016

Hua, G. R., Jin, G. H., \& Liu, Z. Y. (2016). Policy Uncertainty, Investor Emotion and Enterprise Investment: An Empirical Study Based on Strategic Emerging Industries. Journal of Central University of Finance and Economics, 5, 60-69.

Isen, A. M., \& Patrick, R. (1983). The Effect of Positive Feelings on Risk Taking: When the Chips Are Down. Organizational Behavior and Human Performance, 31, 194-202. https://doi.org/10.1016/0030-5073(83)90120-4

James, C., \& Edmister, R. O. (1983). The Relation between Common Stock Returns Trading Activity and Market Value. Journal of Finance, 38, 1075-1086. https://doi.org/10.1111/j.1540-6261.1983.tb02283.x

Johnson, E. J., \& Tversky, A. (1983). Affect, Generalization, and the Perception of Risk. Journal of Personality and Social Psychology, 45, 20-31. https://doi.org/10.1037/0022-3514.45.1.20

Keim, D. B. (1983). Size-Related Anomalies and Stock Return Seasonality: Further Empirical Evidence. Journal of Financial Economics, 12, 12-32. https://doi.org/10.1016/0304-405X(83)90025-9

Lee, C. M. C., Shleifer, A., \& Thaler, R. H. (1991). Investor Sentiment and the Closed-End Fund Puzzle. The Journal of Finance, 46, 75-109. https://doi.org/10.1111/j.1540-6261.1991.tb03746.x

Liu, J., Stambaugh, R. F., \& Yuan, Y. (2019). Size and Value in China. Journal of Financial Economics, 134, 48-69. https://doi.org/10.1016/j.jfineco.2019.03.008

Liu, L. W., |\& Wang, Z. (2016). An Empirical Study on the Influence of Investor Sentiment on the Returns of Different Types of Stocks. Financial Theory and Practice, 2, 90-97.

Meng, Y., \& Chang, J. (2019). Influence of Investor Sentiment on Size Effect. Statistics and Information Forum, 34, 98-104.

Neal, R., \& Wheatley, S. M. (1998). Adverse Selection and Bid-Ask Spreads: Evidence from Closed-End Funds. Journal of Financial Markets, No. 1, 121-149. https://doi.org/10.1016/S1386-4181(97)00011-6

Qadan, M., \& Aharon, D. Y. (2019). Can Investor Sentiment Predict the Size Premium? International Review of Financial Analysis, 63, 10-26. https://doi.org/10.1016/j.irfa.2019.02.005

Schwarz, N., \& Clore, G. L. (1983). Mood, Misattribution, and Judgments of Well-Being: Informative and Directive Functions of Affective States. Journal of Personality and Social Psychology, 45, 513. https://doi.org/10.1037/0022-3514.45.3.513

She, J., \& Chen, X. H. (2005). Equity Size, Volatility and Small-Cap Stock Effect: An Empirical Study from Shanghai and Shenzhen Stock Markets. Systems Engineering, 11, $18-22$.

Shleifer, A. (2000). Inefficient Markets: An Introduction to Behavioral Finance. Oxford University Press, 369-374.

Song, S. X., \& Jin, W. G. (1995). An Empirical Study on the Efficiency of Shanghai Stock Market. Economist, No. 4, 107-113 + 127-128.

Stein, J. C. (1996). Rational Capital Budgeting in an Irrational World. Journal of Business, 69, 429-455. https://doi.org/10.1086/209699

Swaminathan, B. (1996). Time-Varying Expected Small Firm Returns and Closed-End 
Fund Discounts. The Review of Financial Studies, 9, 845-887.

https://doi.org/10.1093/rfs/9.3.845

Wei, Q. (2014). Study on Size Effect of Shanghai A-Share Market from 1996 to 2009: Predictability Based on Revenue. Journal of Industrial Engineering and Engineering Management, 28, 74-80 + 93 .

Wei, X. J., Xia, W. L., \& Sun, T. T. (2014). Research on Measurement of Investor Sentiment in A-Share Market Based on BW Model. Management Observation, 33, 71-73 + 76.

Yang, C. J., \& Xing, J. (1998). Empirical Test of CAPM in Shanghai Stock Market. Journal of Shanghai Jiao Tong University, No. 3, 61-66.

Yi, Z. G., \& Mao, N. (2009). Research on Investor Sentiment Measurement in Chinese Stock Market: The Construction of CICSI. Financial Research, 11, 174-184.

Zhang, Q., Yang, S., \& Yang, H. (2007). An Empirical Study on Investor Sentiment and Stock Returns in China's Stock Market. Systems Engineering, No. 7, 13-17.

Zhang, X. J., Xu, J., \& Guo, L. (2004). An Empirical Study on the "Size Effect" of Shanghai Stock Market. Management Science, 3, 35-38.

Zhou, L. J. (2002). The Size Effect of Chinese Stock Market. Economic Management, 10, 68-75.

Zuo, H. M., \& Liu, Z. T. (2011). Jump Risk Measurement and Its Application in the Test of Risk-Return Relationship. Financial Research, 10, 170-184. 